\title{
EVALUATION OF FECONOMICS AND MINI-FLOTAC AS RECENT STOOL PREPARATION TECHNIQUES FOR DIAGNOSIS OF INTESTINAL PARASITES
}

\author{
By \\ MOHAMED M. ABDEL-GAFFAR, GEHAN S. SADEK, SALWA F. OSHIBA*, \\ And EMAN S. ESMAIL, \\ Department of Parasitology, Faculty of Medicine, Menoufia University, Egypt \\ ( ${ }^{*}$ Correspondence: Tel. +201008302957; Email sal_131977@yahoo.com)

\section{Abstract}

Till now there is no gold standard method for diagnosis of intestinal parasitic infections. The present work evaluated the performance of recently developed methods; mini-FLOTAC and Feconomics and to compare them with the old traditional methods. A total of 136 stool samples (collected from diarrheic patients) were analyzed by the newly developed techniques; Feconomics and mini-FLOTAC with three flotation solutions (FS2, FS6 \& FS7) and traditional methods; direct smear and formol ether concentration method (FECM). The total number of positive samples detected by any of the methods was taken as diagnostic "gold" standard for each parasite species (combined results). Sensitivity, negative predictive value and kappa index of agreement were calculated for each method compared to combined results in detection of all parasites. Overall, $93.4 \%$ of the cases were found to be infected with parasites. The most prevalent parasite detected was Cryptosporidium $(25.7 \%)$ while the least detected parasitic infection was Trichostrongylus colubriformis $(8.1 \%)$. The most sensitive method for protozoa detection was Feconomics followed by FECM and mini-FLOTAC FS7 (97\%, 55\% \& 47\% respectively). Also, Feconomics method was the most sensitive for detection of helminths followed by mini-FLOTAC FS7 and mini-FLOTAC FS2 (94\%, $79 \%$ \& $72 \%)$. Feconomics showed good agreement in detection of all parasites while it showed perfect agreement for individual parasite with superiority to all other methods. Mini-FLOTAC showed better performance in detection of helminths compared to protozoa. Feconomics method is a promising technique for detection of all intestinal parasites. It is simple, highly sensitive, time saving and does not require centrifugation. More studies are still needed to clarify the effectiveness of both methods.

Key words: Parasites, Diagnosis, Feconomics, Mini-FLOTAC.

\section{Introduction}

Parasitic infection of the gastrointestinal tract is one of the major health problems all over the world. It affected about 3.5 billion people and caused morbidity in appro-ximately 450 million people globally (Tyoalumun et al, 2016). Treatment of parasitic diseases depended mainly on reliability, performance and costs of diagnostic tests (Nikolay et al, 2014). Microscopic examination of stool specimens was essential for diagnosis of intestinal parasites (McHardy et al, 2014). The direct wet smear and the concentration techniques were considered to be the most common technique used in detecting intestinal parasites (Mergani et al, 2014). Concentration of stool samples allows detection of parasites of low numbers in the specimen, which might be missed by using only the wet smear (Ogu- oma and Ekwunife, 2006). There were two types of concentration methods; sedimentation and flotation designed to isolate protozoa, larvae or eggs of helminths from stool by centrifugation or variation in the specific density of the microorganisms (Kurt et al, 2012). Formol ether concentration method (FECM) was the most widely used technique to detect most intestinal parasites especially in poor-resource countries (Suwansaksri et al, 2002). However, most of these methods needed skilled personnel (Parija and Srinivasa, 1999), were time consuming, and often necessitated the specific device for centrifugation (Kurt et al, 2012). Innovative direct diagnostic tools that combine modern technology and sensitivity with affordability and feasibility in the resourcelimited settings was most indicated. So, many diagnostic trials were developed (Barda et al, 2013a; Cringoli et al, 2013). 
Feconomics is a new ready to use kit for concentration of stool samples in parasitelogical diagnosis. It eliminates the need for centrifugation, flotation and creates no debris after the procedure is completed. It was highly effective in the identification of the parasites with lower counts in stool samples, and maintains the morphological integrity of the parasites (Kurt et al, 2012; Koltas et al, 2014). Mini-FLOTAC is a new promising diagnostic technique combining between high sensitivity with low costs. It eliminates the need for centrifugation and includes a closed system for flotation and mixing with separate reading disc. It is based on flotation using different flotation solutions for diagnosis of intestinal helminthic infections in a setting where resources were limited (Assefa et al, 2014; Barda et al, 2014).

The present study aimed to evaluate the performance of recently developed methods; mini-FLOTAC and Feconomics and to compare them with the old traditional methods.

\section{Materials and Methods}

This comparative cross sectional study was carried out in Department of Parasitology, Faculty of Medicine, Menoufia University. The overall study was reviewed and approved by Ethics Committee of Faculty of Medicine, Menoufia University. All patients were given an informed consent form to read and approved before being enrolled into the study.

A total of 136 human stool samples were collected from the Department of Clinical Pathology, Menoufia University Hospitals and Shebin Elkom Tropical Hospital. Stool samples were collected and preserved into formalin 5\%, then examined with four different techniques; direct smear method, formol ether concentration method (FECM), Feconomics method and mini-FLOTAC method using three flotation solutions (FS).

Stool analysis: FECM was performed according to Allen and Ridley (1970) The Feconomics was manufactured by Salubris Inc, Boston, USA. Patent application number (TR): 2010/07549. It consists of a plastic cup containing about $10 \mathrm{ml}$ sodium acetate acetic acid - formalin (SAF) solution and a small plastic bag containing absorbent beads of 1 to $3 \mathrm{~mm}$ in diameter (figure 1c). About two grams of stool were added to this cup then the absorbent beads were added to the mixture and homogenized by shaking manually. After three minutes (time needed for beads to absorb the excess solution and leave the concentrate behind), one drop of the concentrate was mixed with iodine and examined under microscope (Kurt et al, 2012; Koltas et al, 2014). Mini-FLOTAC apparatus consists of two components; the base and the reading disc (figure 1b). FillFLOTAC is a plastic device that facilitates filtration, dilution and homogenization of the sample. It consists of a container, a collector and a filter (Fig. 1a). The flotation solutions were used as described in FLOTAC protocols (Barda et al, 2014). For each sample, mini-FLOTAC was done using 3 different flotation solutions; FS2 [saturated sodium chloride; specific gravity (s.g.) = 1.20], FS6 [magnesium sulfate; s.g. = 1.28] and FS7 [zinc sulfate; s.g. $=1.35$ ]. Three grams from each sample were diluted and homogenized with three $\mathrm{ml}$ formalin $5 \%$. Two $\mathrm{ml}$ of the suspension $(1 \mathrm{~g}$ of stool $+1 \mathrm{ml}$ formalin $5 \%$ ) were directly added to $18 \mathrm{ml}$ of each of the three FSs in the fill-FLOTAC. Then flotation chambers in the miniFLOTAC apparatus were filled with the fecal suspension. After 10 minutes (needed for allowing flotation of cysts and eggs), the microscopic adaptor was attached to the microscope then mini-FLOTAC was placed on the adaptor and examined.

Statistical analysis: Statistical package of social signs SPSS version 20 software (SPSS Inc. Chicago, ILL Company) was adopted, epicalc version 1.02 software and excel sheet to perform the analysis. All data were presented as number and percentage. $\mathrm{Z}$ test was used to compare between two proportions. Chi square test was used to compare two groups of categorical data. Cohen's kappa test (K) (Sim and Wright, 
2005), the sensitivity and negative predictive value (NPV) were done to compare between different methods. $\mathrm{P}$ values $<0.05$ were considered as statistically significant. Receiving operation characteristic (ROC) was done to detect the area under the curve (AUC) for all studied methods compared to the combined results, the greater the area the more accurate the method.

\section{Results}

This study included 136 stool samples. The total number of positive samples detected by any of the methods was taken as diagnostic "gold" standard for each parasite species (combined results). The percentage of samples positive for parasites was found to be $93.4 \%$. Cryptosporidium was the most commonly detected parasite $(25.7 \%)$ followed by Giardia lamblia (16.2\%), Entamoeba histolytica (12.5\%), Fasciola gigantica (11\%), Ascaris lumbricoides (10.3\%) and Ancylostoma duodenale (9.6\%) while the least detected parasite was T. colubriformis $(8.1 \%)$.

The combined results showed significant difference in detection of all parasites when compared to results of each method $(\mathrm{P}<$ $0.05)^{*}$ except for Feconomics $(\mathrm{P}>0.05)$. Feconomics significantly showed better results when compared to the other methods regarding detection of all parasites $(\mathrm{P}<$ $0.05)^{*}$.

The current study showed that direct smear, FECM and Feconomics methods detected higher number of protozoa than helminths with no significant difference (P>0.05) while mini-FLOTAC method with its three different FSs detected higher number of helminths than protozoa with significant difference $(\mathrm{P}<0.05)^{*}$ (table 3$)$. The agreement was calculated by kappa $(\mathrm{K})$ index. Regarding Feconomics, the agreement was good $(\kappa=0.76)$ between it and the combined results in detection of all parasites, while it was perfect $(\kappa=0.91-1.00)$ between them for detection of each parasite alone. Regarding the other five methods, there was poor agreement $(\kappa \leq 0.2)$ between each one and the combined results for all parasites. It was noticed that MF-FS2 showed perfect agreement for detection of $T$. colubriformis while MF-FS7 showed perfect agreement for $A$. duodenale detection (table $4)$. The present study showed that the most sensitive method for protozoa detection was Feconomics followed by FECM and MFFS7 (97\%, 55\% \& 47\% respectively) while the least one was MF-FS6 (36\%). Also, Feconomics method was the most sensitive one for detection of helminths followed by MF-FS7 and MF-FS2 (94\%, 79\% \& $72 \%$ respectively) (table 4). NPV was high for each parasite detected with Feconomics method (> 90\%). Also, NPV was higher for intestinal helminths than intestinal protozoa in mini-FLOTAC with the three FS.

The degree of agreement between all methods for detection of intestinal parasites gave a score of how much homogeneity between techniques. There was perfect agreement between MF-FS7 \& MF-FS2 \& FECM $(\kappa=0.81-1.00)$. Also, there was perfect agreement between MF-FS2 and FECM \& MF-FS6 $(\kappa=0.81-1.00)$. But, Feconomics method gave poor agreement with direct smear method and MF-FS6 $(\kappa<0.2)$ and fair agreement with MF-FS7, MF-FS2 and FECM ( $\kappa=0.21-0.4)$. ROC curve showed that all methods had significant AUC compared to combined results. Feconomics showed the highest AUC $(0.98, \mathrm{P}<0.001)^{*}$, while direct smear showed the least AUC $(0.72, \mathrm{P}=0.030)^{*}$.

Concerning the practical feasibility and costs, Feconomics method was simple and time saving method as it took 3-5 minutes but it is relatively considered an expensive method. Mini-FLOTAC method is cheap method as its components are re-usable after careful cleaning with only FSs are needed to be purchased but it takes long time (13-15 minutes). Both recent methods had the advantage of the working in closed system and less hazardous to the team. Another advantage was using fresh samples or fixed samples (formalin 5\%), and did not need 
centrifuge apparatus. Regarding cost, availability of reagents and equipment, direct smear method was the cheapest. But, FECM needs centrifuge apparatus which is not always available especially in low resources

Table 1: Prevalence of parasites detected by each studied method.

\begin{tabular}{|l|l|c|c|c|c|c|c|c|c|c|c|c|c|c|}
\hline \multicolumn{1}{r|}{$\begin{array}{c}\text { Methods } \\
\text { Parasites }\end{array}$} & $\begin{array}{c}\text { Combined } \\
(\mathrm{N} 136)\end{array}$ & \multicolumn{2}{c|}{$\begin{array}{c}\text { Direct Method } \\
(\mathrm{N} 136)\end{array}$} & \multicolumn{2}{c|}{$\begin{array}{c}\text { FECM } \\
(\mathrm{N} 136)\end{array}$} & \multicolumn{2}{c|}{$\begin{array}{c}\text { Feconomics } \\
(\mathrm{N} 136)\end{array}$} & \multicolumn{2}{c|}{$\begin{array}{c}\text { MF-FS7 } \\
(\mathrm{N} 136)\end{array}$} & \multicolumn{2}{c|}{$\begin{array}{c}\text { MF-FS6 } \\
(\mathrm{N} 136)\end{array}$} & \multicolumn{2}{c|}{$\begin{array}{c}\text { MF-FS 2 } \\
(\mathrm{N} 136)\end{array}$} \\
\hline & No. & $\%$ & No. & $\%$ & No & $\%$ & No. & $\%$ & No & $\%$ & No & $\%$ & No. & $\%$ \\
\hline Negative & 9 & 6.6 & 81 & 59.6 & 64 & 47.1 & 14 & 10.3 & 59 & 43.4 & 79 & 58.1 & 68 & 50.0 \\
\hline All positive & 127 & 93.4 & 55 & 40.4 & 72 & 52.9 & 122 & 89.7 & 77 & 56.6 & 57 & 41.9 & 68 & 50.0 \\
\hline Protozoa & 74 & 54.4 & 31 & 22.8 & 41 & 30.1 & 72 & 52.9 & 35 & 25.7 & 27 & 19.9 & 30 & 22.1 \\
\hline Cryptosporidium & 35 & 25.7 & 14 & 10.3 & 19 & 14.0 & 34 & 25.0 & 14 & 10.3 & 11 & 8.1 & 13 & 9.6 \\
\hline G. lamblia & 22 & 16.2 & 10 & 7.4 & 13 & 9.6 & 21 & 15.4 & 11 & 8.1 & 9 & 6.6 & 10 & 7.4 \\
\hline E. histolytica & 17 & 12.5 & 7 & 5.1 & 9 & 6.6 & 17 & 12.5 & 10 & 7.4 & 7 & 5.1 & 7 & 5.1 \\
\hline Helminths & 53 & 39.0 & 24 & 17.6 & 31 & 22.8 & 50 & 36.8 & 42 & 30.9 & 30 & 22.0 & 38 & 27.8 \\
\hline F. gigantica & 15 & 11.0 & 7 & 5.1 & 9 & 6.6 & 15 & 11.0 & 11 & 8.1 & 7 & 5.1 & 10 & 7.3 \\
\hline A. lumbricoides & 14 & 10.3 & 6 & 4.4 & 9 & 6.6 & 13 & 9.6 & 11 & 8.1 & 10 & 7.4 & 10 & 7.3 \\
\hline T. colubriformis & 11 & 8.1 & 5 & 3.7 & 6 & 4.4 & 10 & 7.4 & 9 & 6.6 & 6 & 4.4 & 10 & 7.3 \\
\hline A. duodenale & 13 & 9.6 & 6 & 4.4 & 7 & 5.1 & 12 & 8.8 & 11 & 8.1 & 7 & 5.1 & 8 & 5.9 \\
\hline
\end{tabular}

FECM: Formol ether concentration method, MF-FS: mini-FLOTAC by flotation solution, N: Number

Table 2: Comparison of all studied methods with combined results and with each other for detection of all parasites.

\begin{tabular}{|l|l|l|l|l|l|l|l|l|l|l|l|l|l|l|}
\hline & \multicolumn{2}{l}{$\begin{array}{l}\text { Combined results } \\
(127 / 93.4 \%)\end{array}$} & $\begin{array}{l}\text { Direct smear } \\
(55 / 40.4 \%)\end{array}$ & \multicolumn{2}{l}{$\begin{array}{l}\text { FECM } \\
(72 / 52.9 \%)\end{array}$} & \multicolumn{2}{l}{$\begin{array}{l}\text { Feconomics } \\
(122 / 89.7 \%)\end{array}$} & \multicolumn{2}{l|}{$\begin{array}{l}\text { MF-FS7 } \\
(77 / 56.6 \%)\end{array}$} & $\begin{array}{l}\text { MF-FS6 } \\
(57 / 41.9 \%)\end{array}$ & $\begin{array}{l}\text { MF-FS2 } \\
(68 / 50 \%)\end{array}$ \\
\hline & $\mathrm{Z}$ & $\mathrm{P}$ & $\mathrm{Z}$ & $\mathrm{P}$ & $\mathrm{Z}$ & $\mathrm{P}$ & $\mathrm{Z}$ & $\mathrm{P}$ & $\mathrm{Z}$ & $\mathrm{P}$ & $\mathrm{Z}$ & $\mathrm{P}$ & $\mathrm{Z}$ & $\mathrm{P}$ \\
\hline Combined results & & & & & & & & & & & & & & \\
\hline Direct smear & 9.15 & $0.00^{*}$ & & & & & & & & & & & & \\
\hline FECM & 7.39 & $0.00^{*}$ & 1.94 & 0.05 & & & & & & & & & & \\
\hline Feconomics & 0.87 & 0.38 & 8.71 & $0.00^{*}$ & 6.57 & $0.00^{*}$ & & & & & & & & \\
\hline MF-FS7 & 6.86 & $0.00^{*}$ & 2.55 & $0.01^{*}$ & 0.49 & 0.62 & 6.02 & $0.00^{*}$ & & & & & & \\
\hline MF-FS6 & 8.94 & $0.00^{*}$ & 0.49 & 0.62 & 1.7 & 0.08 & 8.18 & $0.00^{*}$ & 2.30 & $0.02^{*}$ & & & & \\
\hline MF-FS2 & 7.81 & $0.00^{*}$ & 1.83 & 0.06 & 0.36 & 0.71 & 7.00 & $0.00^{*}$ & 0.97 & 0.33 & 1.22 & 0.22 & & \\
\hline
\end{tabular}

FECM: Formol ether concentration method, MF-FS: mini-FLOTAC by flotation solution, N: Number of positive samples, \%:

Percentage Z: Z test to compare to proportions, P: P value, *: Significant difference.

Table 3: Comparison between protozoa and helminths detection by each method.

\begin{tabular}{|c|c|c|c|c|}
\hline Variable & $\begin{array}{l}\text { Protozoa detected by combined } \\
\text { results (Positive results }=74)\end{array}$ & $\begin{array}{l}\text { Helminths detected by combined } \\
\text { results (Positive results }=53 \text { ) }\end{array}$ & $\operatorname{Chi}^{2}\left(\chi^{2}\right)$ & P value \\
\hline $\begin{array}{l}\text { Direct smear } \\
\text { Positive N }(\%) \\
\text { Negative N }(\%)\end{array}$ & $\begin{array}{l}31(41.9) \\
43(58.1)\end{array}$ & $\begin{array}{l}24(45.3) \\
29(54.7)\end{array}$ & 0.145 & 0.72 \\
\hline $\begin{array}{l}\text { FECM } \\
\text { Positive N (\%) } \\
\text { Negative N }(\%)\end{array}$ & $\begin{array}{c}41(55.4) \\
33(44.66)\end{array}$ & $\begin{array}{l}31(58.5) \\
22(41.5)\end{array}$ & 0.120 & 0.86 \\
\hline $\begin{array}{l}\text { Feconomics } \\
\text { Positive N (\%) } \\
\text { Negative N (\%) }\end{array}$ & $\begin{aligned} 72 & (97.3) \\
2 & (2.7)\end{aligned}$ & $\begin{array}{l}50(97.3) \\
3(2.7)\end{array}$ & 0.714 & 0.64 \\
\hline $\begin{array}{l}\text { MF-FS7 } \\
\text { Positive N (\%) } \\
\text { Negative N (\%) }\end{array}$ & $\begin{array}{l}35(47.3) \\
39(52.7) \\
\end{array}$ & $\begin{array}{l}42(79.2) \\
11(20.8) \\
\end{array}$ & 13.20 & $0.00^{*}$ \\
\hline $\begin{array}{l}\text { MF-FS6 } \\
\text { Positive N (\%) } \\
\text { Negative N (\%) }\end{array}$ & $\begin{array}{l}27(36.5) \\
47(63.5)\end{array}$ & $\begin{array}{l}30(56.6) \\
23(43.4)\end{array}$ & 5.052 & $0.03^{*}$ \\
\hline $\begin{array}{l}\text { MF-FS2 } \\
\text { Positive N (\%) } \\
\text { Negative N (\%) }\end{array}$ & $\begin{array}{l}30(40.5) \\
44(59.5)\end{array}$ & $\begin{array}{l}38(71.7) \\
15(28.3)\end{array}$ & 12.05 & $0.001^{*}$ \\
\hline
\end{tabular}

FECM: Formol ether concentration method, MF-FS: mini-FLOTAC by flotation solution, N: Number, \%: Percentage,

*: Significant difference. 
Table 4: K, sensitivity and NPV of each method compared to combined results for detection of each parasites.

\begin{tabular}{|c|c|c|c|c|c|c|c|}
\hline & & Direct smear & FECM & Feconomics & MF- FS7 & MF- FS6 & MF- FS2 \\
\hline Protozoa & $\begin{array}{l}\mathrm{K} / \mathrm{P} \\
\mathrm{S} \\
\mathrm{NPV}\end{array}$ & $\begin{array}{l}0.14 / 0.014 \\
42 \% \\
17 \%\end{array}$ & $\begin{array}{l}0.21 / 0.002^{*} \\
55 \% \\
21 \%\end{array}$ & $\begin{array}{l}0.89 / 0.000^{*} \\
97 \% \\
82 \%\end{array}$ & $\begin{array}{l}0.16 / 0.007 \\
47 \% \\
19 \%\end{array}$ & $\begin{array}{l}0.11 / 0.027 \\
36 \% \\
16 \%\end{array}$ & $\begin{array}{l}0.13 / 0.017 \\
41 \% \\
17 \%\end{array}$ \\
\hline Cryptosporidium & $\begin{array}{l}\mathrm{K} / \mathrm{P} \\
\mathrm{S} \\
\mathrm{NPV}\end{array}$ & $\begin{array}{l}0.21 / 0.022 \\
40 \% \\
30 \%\end{array}$ & $\begin{array}{l}0.33 / 0.003^{*} \\
54 \% \\
36 \%\end{array}$ & $\begin{array}{l}0.93 / 0.000^{*} \\
97 \% \\
90 \%\end{array}$ & $\begin{array}{l}0.21 / 0.002^{*} \\
40 \% \\
30 \%\end{array}$ & $\begin{array}{l}0.16 / 0.052 \\
31 \% \\
27 \%\end{array}$ & $\begin{array}{l}0.20 / 0.029 \\
37 \% \\
29 \%\end{array}$ \\
\hline G. Lamblia & $\begin{array}{l}\mathrm{K} / \mathrm{P} \\
\mathrm{S} \\
\mathrm{NPV}\end{array}$ & $\begin{array}{l}0.33 / 0.14 \\
45 \% \\
43 \%\end{array}$ & $\begin{array}{l}0.46 / 0.002^{*} \\
59 \% \\
50 \%\end{array}$ & $\begin{array}{l}0.92 / 0.000^{*} \\
95 \% \\
90 \%\end{array}$ & $\begin{array}{l}0.37 / 0.008 \\
50 \% \\
45 \%\end{array}$ & $\begin{array}{l}0.29 / 0.023 \\
41 \% \\
41 \%\end{array}$ & $\begin{array}{c}0.33 / 0.014 \\
45 \% \\
43 \%\end{array}$ \\
\hline E. histolytica & $\begin{array}{l}\mathrm{K} / \mathrm{P} \\
\mathrm{S} \\
\mathrm{NPV}\end{array}$ & $\begin{array}{l}0.33 / 0.024 \\
41 \% \\
47 \%\end{array}$ & $\begin{array}{l}0.44 / 0.007 \\
53 \% \\
53 \%\end{array}$ & $\begin{array}{l}1.00 / 0.000^{*} \\
100 \% \\
100 \%\end{array}$ & $\begin{array}{l}0.50 / 0.003^{*} \\
59 \% \\
56 \%\end{array}$ & $\begin{array}{l}0.33 / 0.024 \\
41 \% \\
47 \%\end{array}$ & $\begin{array}{l}0.33 / 0.024 \\
41 \% \\
47 \%\end{array}$ \\
\hline Helminths & $\begin{array}{l}\mathrm{K} / \mathrm{P} \\
\mathrm{S} \\
\mathrm{NPV}\end{array}$ & $\begin{array}{l}0.19 / 0.10 \\
45 \% \\
24 \%\end{array}$ & $\begin{array}{l}0.29 / 0.001^{*} \\
58 \% \\
29 \%\end{array}$ & $\begin{array}{l}0.83 / 0.000^{*} \\
94 \% \\
75 \%\end{array}$ & $\begin{array}{l}0.53 / 0.000^{*} \\
79 \% \\
45 \%\end{array}$ & $\begin{array}{l}0.28 / 0.002^{*} \\
57 \% \\
28 \%\end{array}$ & $\begin{array}{l}0.42 / 0.000^{*} \\
72 \% \\
38 \%\end{array}$ \\
\hline F. gigantica & $\begin{array}{l}\mathrm{K} / \mathrm{P} \\
\mathrm{S} \\
\mathrm{NPV}\end{array}$ & $\begin{array}{l}0.40 / 0.015 \\
47 \% \\
53 \%\end{array}$ & $\begin{array}{l}0.53 / 0.003^{*} \\
60 \% \\
60 \%\end{array}$ & $\begin{array}{l}1.00 / 0.000^{*} \\
100 \% \\
100 \%\end{array}$ & $\begin{array}{l}0.67 / 0.000^{*} \\
73 \% \\
69 \%\end{array}$ & $\begin{array}{l}0.40 / 0.015 \\
47 \% \\
53 \%\end{array}$ & $\begin{array}{l}0.60 / 0.001^{*} \\
67 \% \\
64 \%\end{array}$ \\
\hline A. lumbricoides & $\begin{array}{l}\mathrm{K} / \mathrm{P} \\
\mathrm{S} \\
\mathrm{NPV}\end{array}$ & $\begin{array}{l}0.37 / 0.022 \\
43 \% \\
53 \%\end{array}$ & $\begin{array}{l}0.59 / 0.002^{*} \\
64 \% \\
64 \%\end{array}$ & $\begin{array}{l}0.91 / 0.000^{*} \\
93 \% \\
90 \%\end{array}$ & $\begin{array}{l}0.74 / 0.000 * \\
79 \% \\
75 \%\end{array}$ & $\begin{array}{l}0.66 / 0.001^{*} \\
71 \% \\
69 \%\end{array}$ & $\begin{array}{l}0.66 / 0.001^{*} \\
71 \% \\
69 \%\end{array}$ \\
\hline T. colubriformis & $\begin{array}{l}\mathrm{K} / \mathrm{P} \\
\mathrm{S} \\
\mathrm{NPV}\end{array}$ & $\begin{array}{l}0.43 / 0.020 \\
45 \% \\
60 \%\end{array}$ & $\begin{array}{l}0.52 / 0.008 \\
55 \% \\
64 \%\end{array}$ & $\begin{array}{l}0.90 / 0.000^{*} \\
91 \% \\
90 \%\end{array}$ & $\begin{array}{l}0.80 / 0.000 \\
82 \% \\
82 \%\end{array}$ & $\begin{array}{l}0.52 / 0.008 \\
55 \% \\
64 \%\end{array}$ & $\begin{array}{l}0.90 / 0.000 * \\
91 \% \\
90 \%\end{array}$ \\
\hline A. duodenale & $\begin{array}{l}\text { K/P } \\
\text { S } \\
\text { NPV }\end{array}$ & $\begin{array}{l}0.41 / 0.017 \\
46 \% \\
56 \%\end{array}$ & $\begin{array}{l}0.49 / 0.008 \\
54 \% \\
60 \%\end{array}$ & $\begin{array}{l}0.91 / 0.000^{*} \\
92 \% \\
90 \%\end{array}$ & $\begin{array}{l}0.82 / 0.000 \\
85 \% \\
82 \%\end{array}$ & $\begin{array}{l}0.49 / 0.008 \\
54 \% \\
60 \%\end{array}$ & $\begin{array}{l}0.57 / 0.003^{*} \\
85 \% \\
82 \%\end{array}$ \\
\hline All parasites & $\begin{array}{l}\mathrm{K} / \mathrm{P} \\
\mathrm{S} \\
\mathrm{NPV}\end{array}$ & $\begin{array}{l}0.09 / 0.011 \\
43 \% \\
11 \%\end{array}$ & $\begin{array}{l}0.15 / 0.001^{*} \\
57 \% \\
14 \%\end{array}$ & $\begin{array}{l}0.76 / 0.000^{*} \\
96 \% \\
64 \%\end{array}$ & $\begin{array}{l}0.17 / 0.000^{*} \\
61 \% \\
15 \%\end{array}$ & $\begin{array}{l}0.10 / 0.008 \\
45 \% \\
11 \%\end{array}$ & $\begin{array}{l}0.13 / 0.002^{*} \\
54 \% \\
13 \%\end{array}$ \\
\hline
\end{tabular}

FECM: Formol ether concentration method, MF-FS: mini-FLOTAC by flotation solution, K: kappa test, P: Pvalue, ${ }^{*}$ : signify cant difference, S: sensitivity, NPV: negative predictive value.

Table 5: Kappa index for agreement between different methods for detection of all parasites.

\begin{tabular}{|l|c|c|c|c|c|c|}
\hline Methods & Direct smear & FECM & Feconomics & MF-FS7 & MF-FS6 & MF-FS2 \\
\hline Direct smear & & & & & & \\
\hline FECM & 0.75 & & & & & \\
\hline Feconomics & 0.15 & 0.23 & & & & \\
\hline MF-FS7 & 0.68 & 0.93 & 0.26 & & & \\
\hline MF-FS6 & 0.97 & 0.78 & 0.15 & 0.71 & & \\
\hline MF-FS2 & 0.80 & 0.94 & 0.21 & 0.87 & 0.84 & \\
\hline
\end{tabular}

FECM: Formol ether concentration method, MF--FS: mini-FLOTAC by flotation

\section{Discussion}

The present study showed that the overall prevalence of intestinal parasitic infection was $93.4 \%$. This high prevalence may be attributed to that most of the samples were collected from the Tropical Hospital, also to the fact that all samples were of diarrheic patients. There are some reports showing the same higher prevalence, for example, a prevalence of $94 \%$ was recorded by Abdel-Hafeez et al. (2012) and $90 \%$ was reported by Alwabr and Al-Moayed (2016). In contrary to the results, Tulu et al. (2016) showed a prevalence of $26.6 \%$ in Ethiopia.
In the present work, the direct smear method showed the least sensitivity for all parasites (43\%) compared to FECM (57\%). The current findings coincide to some extent with the study done by Yimer et al. (2015) in Ethiopia as the sensitivity by the same two methods was $48.9 \%$ \& $63.1 \%$ respectively. Also, the present results coincided with Mergani et al. (2014) who found the superiority of concentration techniques including FECM over direct smear microscopy with a significant difference. 
Feconomics showed distinctive higher sensitivity for detection of all parasites and also for individual parasites when compared to all other methods. This result agreed Koltas et al. (2014) who reported higher sensitivity of Feconomics and its superiority over FECM and direct smear method. The same authors recommended it to be the routine diagnostic method in rural areas in the developing countries. The superiority of Feconomics could be attributed to the absorbent beads that help homogenization and concentration of the samples leading to clarity of sediment and lack of debris (Kurt et al, 2012).

Regarding mini-FLOTAC, the diagnostic accuracy varied according to the FS used. The MF-FS7 showed best sensitivity compared to MF-FS2 and MF-FS6. Moreover, the sensitivity of MF-FS7 was higher than that obtained by direct method and FECM regarding detection of all parasites. Besides, the current work demonstrated that miniFLOTAC method with the three FSs significantly detected higher number of helminths more than protozoa with significant difference $(\mathrm{P}<0.05)^{*}$, however, the other methods did not show significant difference in detection of helminths and protozoa. Barda et al. (2013a) demonstrated that miniFLOTAC showed higher sensitivity of detection of helminths than protozoa and also the sensitivity of detection of helminths was higher when compared to direct method and FECM. This poor performance for protozoal detection may be due to the debris resulting from the high specific gravity of FSs which made the field unclear. Also, the reading disk of the mini-FLOTAC method together with examination using $400 \mathrm{X}$ at maximum did not allow perfect visibility of internal structures. This observation was noticed also by Barda et al. (2013a) and centrifugation was proposed to overcome this issue.

The present study showed that NPV for Feconomics method in detection of all and individual parasites was the best compared to other methods. MF-FS7 showed poor NPV for all parasites. In contrast, some reports showed higher NPV for miniFLOTAC technique than those of the current work (Barda et al, 2014). The agreement among studied techniques for detection of all parasites was measured. There was a perfect agreement between MF- FS7 and MF- FS2 which agreed with Barda et al. (2014). However, Barda et al. (2013b) showed only good agreement between them. Also, the present study showed perfect agreement between MF- FS7 and FECM which was consistent with Barda et al. (2013a). ROC curve was constructed to detect the AUC for studied techniques compared to combined result to demonstrate which method was the best. All studied methods showed good significant AUC, however, the best was for Feconomics followed by MF-FS7.

Concerning the practical feasibility and cost of the currently used techniques, Barda et al. (2013a; 2014) supported the present study. There was a limitation to this work as it did not assess the quantitative performance of mini-FLOTAC method and did not compare it to any other diagnostic quantitative method.

\section{Conclusion}

Feconomics method proved to be a promising high performance technique for detection of all intestinal parasites; protozoa and helminths. It is simple, highly sensitive, time saving and does not require centrifugation. In addition, it is considered less hazardous to working team. Mini-FLOTAC is an effective method mainly in diagnosis of helminths, relatively cheaper; however it still needs some modifications in the apparatus and trials with other flotation solutions that may improve its results. More studies are still needed to clarify the effectiveness of both methods.

\section{References}

Abdel-Hafeez, EH, Ahmad, AK, Ali, BA, Moslam FA, 2012: Opportunistic parasites among 
immunosuppressed children in Minia District, Egypt. Korean J. Parasitol. 50, 1:57-62.

Allen AV, Ridley DS, 1970: Further observations on the formol-ether concentration technique for fecal parasites. J. Clin. Pathol. 23, 6:5456.

Alwabr G, Al-Moayed E, 2016: Prevalence of intestinal parasitic infections among school children of Al-Mahweet Governorate, Yemen. Eur. J. Biol. Res. 6, 2:64-73.

Assefa, LM, Crellen, T, Kepha, S, Kihara, J H, Njenga, SM, et al, 2014: Diagnostic accuracy and cost-effectiveness of alternative methods for detection of soil-transmitted helminths in a post-treatment setting in Western Kenya. PLoS Negl. Trop. Dis. 8, 5:2843.

Barda, B, Rinaldi, L, Lanniello, D, Zepherine, H, Salvo F, et al, 2013a: Mini-FLOTAC, an innovative direct diagnostic technique for intestinal parasitic infections: experience from the field. PLoS Negl. Trop. Dis. 7, 8:2344.

Barda, B, Cajal, P, Villagran, E, Cimino, R, Juarez, M, et al, 2013b: Mini-FLOTAC and Kato-Katz: helminth eggs watching on the shore of lake Victoria. Parasit. Vectors 6, 1:220.

Barda, B, Cajal, P, Villagran, E, Cimino, R, Ju-arez, M, et al, 2014: Mini-FLOTAC, KatoKatz \& McMaster: three methods, one goal; highlights from North Argentina. Parasit. Vectors 7:271-8.

Cringoli, G, Rinaldi, L, Albonico, M, Bergquist, $\mathbf{R}$, Utzinger, J, 2013: Geospatial(s) tools: Integration of advanced epidemiological sampling and novel diagnostics. Geospat. Hlth. 7, 2: 399-404.

Koltas, IS, Akyar, I, Elgun, G, Kocagoz, T, 2014: Feconomics; a new and more convenient method, the routine diagnosis of intestinal parasittic infections. Parasitol. Res. 113, 7:25038.

Kurt, O, Akyar, I, Gorgun, S, Kocagoz, T, Ozbilgin, A, 2012: Feconomics: a simple, novel and fast technique for stool concentration in parasitology laboratory. Kafkas Univ. Vet. Fak. Derg. 18:161-5.
McHardy, IH, Wu, M, Shimizu-Cohen, R, Couturier, MR, Humphries, RM, 2014: Detection of intestinal protozoa in the clinical laboratory. J. Clin. Microbiol. 52, 3:712-20.

Mergani, MH, Mohammed, MA, Khan, N, Ba-no, M, Khan, AH, 2014: Detection of intestinal protozoa by using different methods. Dentist. Med. Res. J. 2:28-32.

Nikolay, B, Brooker, SJ, Pullan, RL, 2014: Sensitivity of diagnostic tests for human soiltransmitted helminth infections: a meta-analysis in the absence of a true gold standard. Int. J. Parasitol. 44, 11:765-74.

Oguoma, V, Ekwunife, C, 2006: The need for a better method: comparison of direct smear and formol-ether concentration techniques in diagnosing intestinal parasites. Internet J. Trop. Med. 3, 2: 1-6.

Parija, SC, Srinivasa, 1999: Viewpoint: Neglect of stool microscopy for intestinal parasites \& po-ssible solutions. Trop. Med. Int. Hlth. 4, 7:522-4.

Sim, J, Wright, CC, 2005: The kappa statistic in reliability studies: use, interpretation, and sample size requirements. Phys. Ther. 85, 3:25768.

Suwansaksri, J, Nithiuthai, S, Wanitkit, V, Soogarun, S, Palatho, P, 2002: The formolether concentration technique for intestinal parasite comparing $0.1 \mathrm{n}$ sodium hydroxide with normal saline preparations. Southeast Asian J. Trop. Med. Publ. Hlth. 33:97-8.

Tulu, B, Taye, S, Zenebe, Y, Amsalu, E, 2016: Intestinal parasitic infections and nutritional status among primary school children in Delomena District, South Eastern Ethiopia. Iran J. Parasitol. 11, 4:549-58.

Tyoalumun, K, Abubakar, S, Christopher, N, 2016: Prevalence of intestinal parasitic infections and their association with nutritional status of rural and urban pre-school children in Benue State, Nigeria. Int. J. MCH/AIDS 5, 2:146-52.

Yimer, M, Hailu, T, Mulu, W, Abera, B, 2015: Evaluation performance of diagnostic methods of intestinal parasitosis in school age children in Ethiopia. BMC. Res. Notes.8:820.

\section{Explanation of figures}

Fig. 1: a) Fill-FLOTAC, b) Mini-FLOTAC disc, c) Feconomics

Fig. 2: Fasciola gigantica eggs by iodine stained smear (X400) a: Direct method, b: FECM, c: Mini-FLOTAC FS7 \& d: Feconomics method.

Fig. 3: Cryptosporidium oocyst by iodine stained smear (X1000) a: Direct method, b: FECM, c: Mini-FLOTAC FS7 \& d: Feconomics method

Fig. 4: Receiving operation characteristics (ROC) curve analysis of different methods in detection of parasites compared to combined result. 

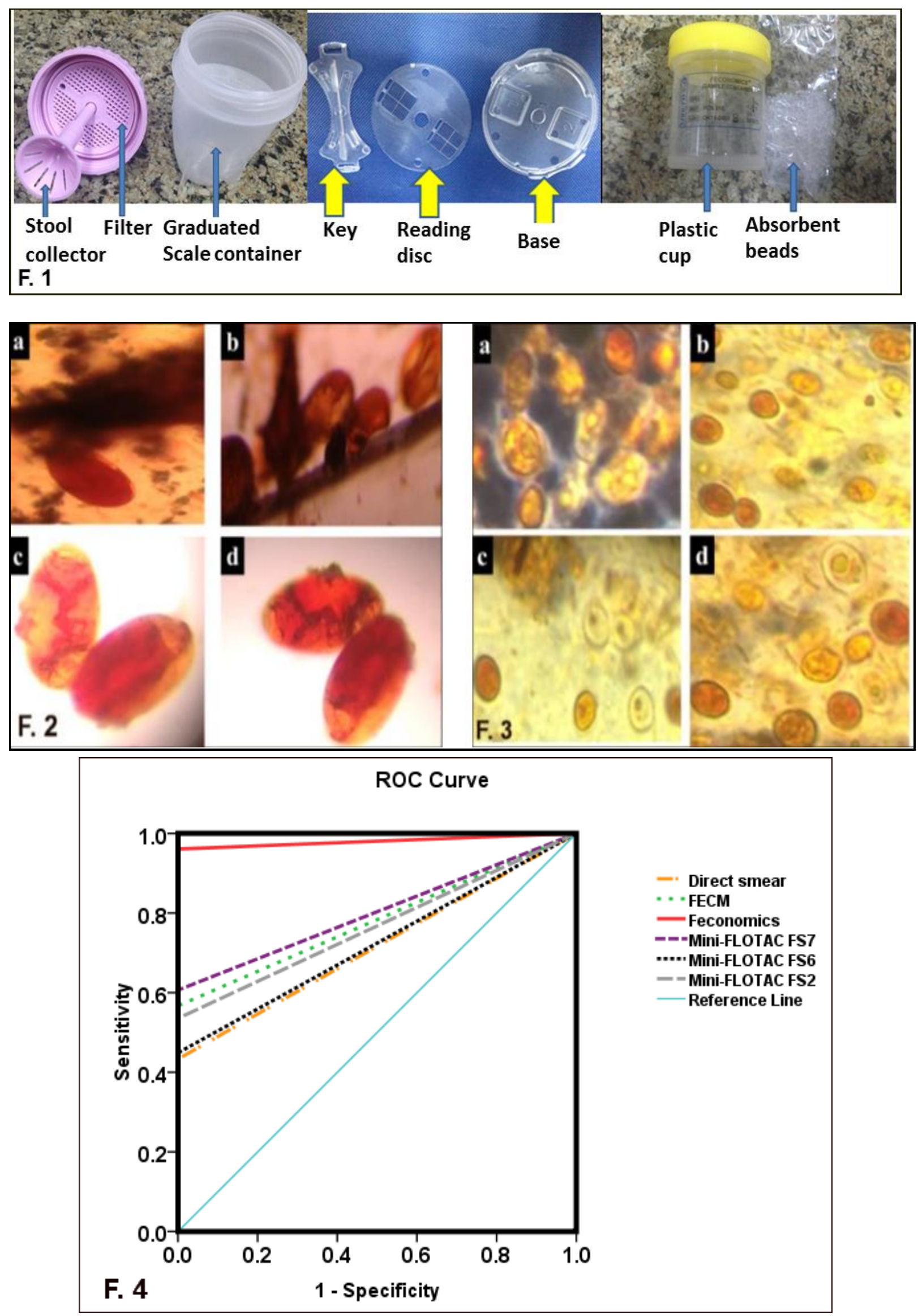